\title{
STUDI AWAL KESESUAIAN LAHAN BUDIDAYA UDANG VANNAME (LITOPENAEUS VANNAMEI) DI MUARA SUNGAI SIBUNDONG KABUPATEN TAPANULI TENGAH PROVINSI SUMATERA UTARA
}

\author{
Preliminary Study Of Land Fitness For Vanname Shrimp Culture (Litopenaeus \\ vannamei) In Sibundong River Estuary, Central Tapanuli District, North Sumatera \\ Province
}

\author{
Arsanti $^{1}$, Rodhi Firmansyah ${ }^{2}$, Susi $\mathrm{Mei}^{3}$, Nida Farah ${ }^{3}$, Nur Ummi Sibuea ${ }^{3}$ \\ ${ }^{1}$ Sekolah Tinggi Perikanan dan Kelautan Matauli, Tapanuli Tengah, Sumatera Utara \\ ${ }^{2}$ Sekolah Tinggi Perikanan dan Kelautan Matauli, Tapanuli Tengah, Sumatera Utara \\ ${ }^{3}$ Mahasiswi Sekolah Tinggi Perikanan dan Kelautan Matauli, Tapanuli Tengah, \\ Sumatera Utara \\ *Email ${ }^{1}$ : arsanti.arsanti@yahoo.co.id
}

\begin{abstract}
ABSTRAK
Diversifikasi usaha perikanan dan kelautan, khususnya budidaya udang vanname (Litopenaeus vannamei) memerlukan perhatian dan studi yang intensif. Studi kesesuaian lahan untuk budidaya udang vanname dilakukan pada bulan Desember 2018-Februari 2019 yang dititikberatkan pada parameter fisika, kimia serta biologi perairan muara Sungai Sibundong yang nantinya akan menentukan tingkat keberhasilan budidaya. Studi dilakukan dengan pengukuran parameter secara in situ research kemudian dilakukan pembobotan dan perhitungan tingkat pengaruh dari setiap parameter terhadap daerah yang berpotensi untuk budidaya udang. Hasil studi menunjukkan bahwa muara Sungai Sibundong sangat sesuai untuk budidaya udang yang ditunjukkan dengan kisaran suhu antara $24,70^{\circ} \mathrm{C}-24,90^{\circ} \mathrm{C}$, salinitas $0 \mathrm{ppt}$, kecerahan berkisar antara 40-59,16 m, kedalaman berkisar antara 1-1,5 m, pH berkisar antara 7,21-7,91, DO berkisar antara 6,18-6,68 mg/l, Ammonia berkisar antara 0,5-1 $\mathrm{mg} / \mathrm{l}$, dan fosfat berkisar antara $<1 \mathrm{mg} / \mathrm{l}$. Dari wilayah muara Sungai Sibundong yang diteliti, kesemuanya tergolong kedalam kategori sesuai, memenuhi persyaratan minimal (S2). Kesimpulan yang dapat diambil adalah bahwa secara umum adalah bahwa muara Sungai Sibundong, Kabupaten Tapanuli Tengah, Sumatera Utara dapat mendukung pengembangan usaha budidaya udang vanname.
\end{abstract}

Kata kunci: Kesesuaian Lahan Budidaya, Muara Sungai Sibundong, Sorkam, Udang vanname.

\begin{abstract}
Diversification of fisheries and marine businesses, especially vanname shrimp cultivation (Litopenaeus vannamei) requires intensive attention and study. The land suitability study for vanname shrimp cultivation was carried out in December 2018-February 2019 which focused on the physical, chemical and biological parameters of the Sibundong River estuary which would later determine the success rate of cultivation. The study was carried out by measuring parameters in situ research then weighting and calculating the level of influence of each parameter on the area that has the potential for shrimp farming. The results of the study show that the Sibundong River estuary is very suitable for shrimp farming which is indicated by a temperature range between $24.70^{\circ} \mathrm{C}-24.90^{\circ} \mathrm{C}, 0 \mathrm{ppt}$
\end{abstract}


salinity, brightness ranges from 40-59.16 m, depths ranging from 1-1.5 m, pH ranges from 7.21-7.91, DO ranges from 6.18-6.68 $\mathrm{mg} / 1$, Ammonia ranges from $0.5-1 \mathrm{mg} / 1$, and phosphate ranges from $<1 \mathrm{mg} / 1$. From the Sibundong River estuary area studied, all of them fall into the category of suitable, fullfiling the minimum requirement (S2). The conclusion that can be taken is that in general, it is that the estuary of the Sibundong River, Tapanuli Tengah District, North Sumatra Province can support the development of vanname shrimp cultivation.

Keywords: Land Fitness, Sibundong River Estuary, Sorkam, Vanname shrimp.

\section{PENDAHULUAN Latar Belakang}

Potensi Kelautan dan Perikanan di Kabupaten Tapanuli Tengah sangat besar yang secara umum mencakup perikanan tangkap dan budidaya. Menurut data produksi perikanan yang dikeluarkan oleh Pemerintah Kabupaten Tapanuli Tengah (2017), total hasil perikanan mencapai 608,636 ton yang terdiri dari hasil realisasi penangkapan mencapai 40,926 ton, dan total hasil realisasi perikanan budidaya mencapai 567,71 ton. Hasil produksi perikanan tersebut memiliki sumbangsih yang cukup besar kepada Produk Domestik Regional Bruto (PDRB) Kabupaten Tapanuli Tengah. Data PDRB Kabupaten Tapanuli Tengah atas dasar menurut lapangan usaha dari sektor pertanian, kehutanan, dan perikanan mencapai 3.964,67 milyar atau mencapai $46,35 \%$ dari total pendapatan (Badan Pusat Statistik Kabupaten Tapanuli Tengah, 2017).

Diantaranya merupakan hasil tangkapan udang penaied (Penaeus sp) oleh nelayan di perairan Kabupaten Tapanuli Tengah yang mencapai 8.023 ton dengan jumlah tangkapan yang diperbolehkan sebanyak 6.418 ton. Jumlah penangkapan udang penaied tersebut sudah melebihi 1,55 ton dari kapasitas lestari, optimum, dan berkelanjutan (MSY) (Makkasau, 2020). Hal ini menunjukkan bahwa
Kabupaten Tapanuli Tengah masih bergantung pada hasil tangkapan di alam dibandingkan dengan mengadakan kegiatan budidaya.

Data yang diperoleh dari Richmand (2019) menunjukkan bahwa jumlah pembudidaya organisme payau berupa tambak yang berada di Kabupaten Tapanuli Tengah berjumlah 5 (lima) orang pengusaha dimana 2 (dua) orang diantaranya melakukan budidaya udang vanname dengan luas lahan sejumlah 70,2 hektar dari 122 hektar yang tersedia. Bahwasannya minat massyarakat untuk melakukan budidaya udang terutama udang vanname masih sangat rendah.

Dengan masih rendahnya minat masyarakat untuk melakukan budidaya udang vanname tersebut, maka masih terbuka peluang cukup besar untuk dilakukannya pengembangan budidaya secara intensif dengan mencari alternatif lokasi serta metoda budidaya yang sesuai dengan karakteristik lingkungan yang ada di Kabupaten Tapanuli Tengah. Pengembangan perikanan budidaya udang vanname (Litopenaeus vannamei) tersebut diharapkan dapat memacu perkembangan perekonomian daerah yang pada akhirnya meningkatkan penyerapan tenaga kerja di bidang perikanan serta meningkatkan pendapatan/kapita masyarakat 
khususnya di Kecamatan Sorkam dan secara umum di Kabupaten Tapanuli Tengah.

\section{METODE PENELITIAN Waktu dan Tempat}

Penelitian ini dilakukan pada bulan Desember 2018, di muara sungai Sibundong $\left(15^{\circ} 2\right.$ ' 12 'N 98 34'00'E) yang berada di Kelurahan Sorkam Kanan, Kabupaten Tapanuli Tengah Provinsi Sumatera Utara (Gambar 1). Pengambilan sampel dan pengukuran kualitas air (in situ research) dilakukan pada saat perairan di muara sungai dalam keadaan surut dan seusai turun hujan di sepanjang aliran sungai pada pukul 10.00-17.00 wib. Analisis sampel air (pengamatan jasad renik air sungai) (ex situ research) dilakukan di laboratorium Sekolah Tinggi
Perikanan dan Kelautan Matauli dari tanggal 9 Desember hingga tanggal 15 Desember 2018. Pengambilan data primer dan sekunder pada instansi terkait dilakukan di Kecamatan Sorkam Kabupaten Tapanuli Tengah, Kelurahan Sorkam Kiri, Kelurahan Sorkam Kanan, dan Dusun III pada tanggal 21 sampai dengan tanggal 26 Januari 2019. Pengambilan data sekunder pada Badan Pusat Statistik Kabupaten Tapanuli Tengah, Dinas Perikanan dan Kelautan Kabupaten Tapanuli Tengah dengan pengambilan data melalui buku yang diterbitkan oleh Badan Pusat Statistik (Kecamatan Sorkam Dalam Angka 2013, 2014, 2017 dan 2018 (Sorkam District in Figures Nomor Katalog 1102001.1204060)) ataupun data yang dikumpulkan melalui website resmi instansi (httsp://tapanulitengahkab.bps.go.id).

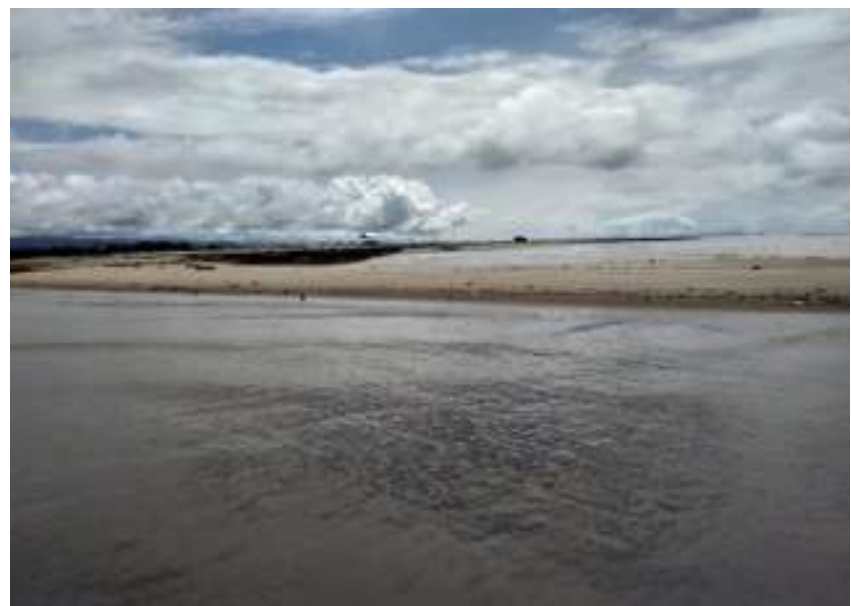

Gambar 1. Muara Sungai Sibundong yang berpotensi dikembangkan sebagai lahan budidaya udang vanname.

\section{Variabel Penelitian}

Variabel yang diukur dalam penelitian ini adalah kualitas air dengan parameter-parameternya, antara lain: suhu, turbiditas (kecerahan-kekeruhan), kecepatan arus sungai, panjang-lebar-dalam muara sungai, salinitas, $\mathrm{pH}$, kelarutan, Dissolved Oxygen (DO/oksigen terlarut), Ammonia $\left(\mathrm{NH}_{3}\right)$, dan Phosphat $\left(\mathrm{PO}^{4}\right)$. 
Bahan dan Alat Penelitian

Tabel 1. Bahan dan Alat Penelitian
Bahan dan alat yang digunakan dalam studi awal ini terangkum dalam Tabel 1, sebagai berikut:

\begin{tabular}{|c|c|}
\hline \multicolumn{2}{|r|}{ Bahan Penelitian } \\
\hline Bahan & Fungsi \\
\hline $\begin{array}{l}\text { 1. Aquades (Air } \\
\text { Steril) }\end{array}$ & $\begin{array}{l}\text { Membersihkan dan mengkalibrasikan peralatan sebelum dan } \\
\text { sesudah digunakan dalam pengambilan sampel di lokasi } \\
\text { penelitian (in situ) dan laboratorium (eks situ). }\end{array}$ \\
\hline 2. Es Batu & $\begin{array}{l}\text { Mengawetkan sampel air dengan metode pendinginan dari } \\
\text { lokasi penelitian sampai dengan laboratorium. } \\
\text { Alat Penelitian }\end{array}$ \\
\hline Alat & Fungsi \\
\hline 1. Secchi Disk & $\begin{array}{l}\text { Alat ukur kecerahan perairan) (Environmental Protection } \\
\text { (Water) Policy, 2009). }\end{array}$ \\
\hline 2. Sterofoam & $\begin{array}{l}\text { Alat pembawa sampel air minim guncangan, berukuran } 100 \\
\text { x } 50 \mathrm{~cm} \text {. }\end{array}$ \\
\hline $\begin{array}{l}\text { 3. Hand } \\
\text { Refractometer }\end{array}$ & Alat ukur salinitas perairan (ICCTF-UNRI, \\
\hline $\begin{array}{l}\text { 4. DO (dissolved } \\
\text { oxygen) meter }\end{array}$ & $\begin{array}{l}\text { Alat ukur oksigen terlarut, Zenith Measuring and Testing } \\
\text { Instruments (ICCTF-UNRI, 2018). }\end{array}$ \\
\hline $\begin{array}{l}\text { 5. Pen Type } \mathrm{pH} \\
\text { meter }\end{array}$ & Alat ukur pH (asam-basa air) (ICCTF-UNRI, 2018). \\
\hline $\begin{array}{l}\text { 6. Termometer } \\
\text { Digital }\end{array}$ & Alat ukur suhu perairan (ICCTF-UNRI, 2018). \\
\hline $\begin{array}{l}\text { 7. Hanna Water } \\
\text { Quality Test Kit }\end{array}$ & $\begin{array}{l}\text { Alat pengukur parameter kualitas air, Hanna Instrument Tipe } \\
\text { H13817 (ICCTF-UNRI, 2018). }\end{array}$ \\
\hline $\begin{array}{l}\text { 8. Phosphate Test } \\
\text { Kit }\end{array}$ & $\begin{array}{l}\text { Alat pengukur kadar posfat, Hanna Instrument HI383 } \\
\text { (ICCTF-UNRI, 2018). }\end{array}$ \\
\hline $\begin{array}{l}\text { 9. Ammonia Test } \\
\text { Kit }\end{array}$ & $\begin{array}{l}\text { Alat pengukur kadar amonia, Hanna Instrument HI3824 } \\
\text { (ICCTF-UNRI, 2018). }\end{array}$ \\
\hline 10. GPS & Alat untuk menentukan posisi titik-titik stasiun penelitian. \\
\hline 11. Stopwatch & $\begin{array}{l}\text { Alat untuk mengukur kecepatan arus dengan menggunakan } \\
\text { metoda pelampung. }\end{array}$ \\
\hline 12. Galah & Alat untuk mengukur kedalaman perairan sepanjang $2 \mathrm{~m}$. \\
\hline $\begin{array}{l}\text { 13. MicroscopCam } \\
\text { dan Video } \\
\text { Capture S-EYE }\end{array}$ & $\begin{array}{l}\text { Alat untuk alat untuk melihat jasad renik di dalam sampel air } \\
\text { sungai yang telah diambil (Yayasan Matauli, 2018). Versi S- } \\
\text { EYE Versi 1.2.4.128 (2015) 2MP. } \\
\text { Peralatan Penelitian Tambahan }\end{array}$ \\
\hline
\end{tabular}

Plastik kantong (hitam), lembar pengamatan kualitas air, botol sampel air plastik untuk mengumpulkan biota perairan, panduan pengamatan, peralatan lapangan pendukung lainnya untuk mengambil sampel air dan tanah, serta kamera untuk kegiatan dokumentasi penelitian di lapangan dan laboratorium.

\section{Metode Penelitian}

Data dalam penelitian ini menggunakan data sekunder dan data primer. Data sekunder merupakan data time series diperoleh melalui studi dokumentasi yang dilakukan dengan cara mengumpulkan dan mencatat berbagai data yang telah dipublikasikan sedemikian rupa oleh pihak lain (Nazir, 2003). Data dalam penelitian ini umumnya bersumber dari Kecamatan Sorkam, Kelurahan 
Sorkam Kiri, Dusun III Kelurahan Sorkam Kiri, Kelurahan Muara Sorkam Kanan, Pemerintahan Kabupaten Tapanuli Tengah, Dinas Kelautan dan Perikanan Kabupaten Tapanuli Tengah, maupun Biro Pusat Statistik Kabupaten Tapanuli Tengah.

\section{Teknik Pengambilan Sampel}

Penelitian dilaksanakan di wilayah Sungai Sibundong Kecamatan Sorkam Kabupaten Tapanuli Tengah Sumatera Utara. Metode yang digunakan dalam penelitian ini adalah metode survei lapangan. Penentuan stasiun penelitian dilakukan dengan pengamatan lapangan yang telah dimulai sebelum penelitian berlangsung dan menganalisis peta dasar yang diperoleh dari Google Earth (2018). Peta dasar tersebut digunakan sebagai peta kerja pada saat melakukan survei di lapangan dalam pengambilan sampel tanah dan air.

Pengamatan atau pengambilan data primer di lapangan dilakukan di 3 (tiga) titik sampling yang mewakili wilayah penelitian (Gambar 2). Stasiun 1 terletak di bagian sebelah kiri, Stasiun 2 terletak di tengah, dan Stasiun 3 terletak di bagian kanan muara Sungai Sibundong. Setiap lokasi pengamatan titik sampling dicatat posisi geografisnya dengan alat penentu posisi (GPS).

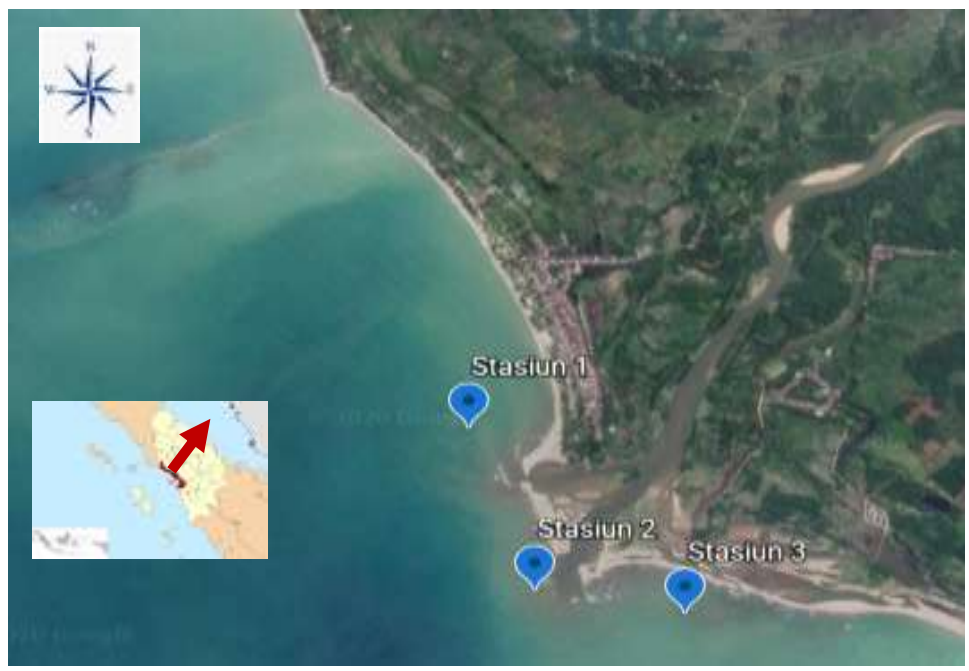

Gambar 2. Stasiun Penelitian di Muara Sungai Sibundong.

\section{Perhitungan Nilai Parameter Kualitas Air}

Hasil pengukuran parameter kualitas air (fisika-kimia-biologi) yang telah dikumpulkan dari 3 (tiga) stasiun penelitian di lapangan dengan
3 (tiga) kali ulangan dan hasil pengamatan di laboratorium, kemudian dirata-ratakan dan diolah yang nantinya akan dianalisis sesuai dengan peruntukannya. 
Tabel 2. Kriteria Skoring dan Pembobotan Kesesuaian Lahan Budidaya Udang Vanname.

\begin{tabular}{|c|c|c|c|c|c|c|}
\hline No & Parameter & Kisaran & $\begin{array}{l}\text { Nilai } \\
(\mathrm{N})\end{array}$ & $\begin{array}{c}\text { Bobot } \\
\text { (B) }\end{array}$ & $\begin{array}{c}\text { Skor } \\
(\mathrm{NxB}) \\
\end{array}$ & $\begin{array}{l}\text { Sumber } \\
\text { Pustaka }\end{array}$ \\
\hline \multirow[t]{3}{*}{1.} & Suhu $\left({ }^{\circ} \mathrm{C}\right)$ & $25-32$ & 3 & \multirow{3}{*}{$(\infty)}$, & 9 & \multirow[t]{3}{*}{ New (2002) } \\
\hline & & $12-25$ & 2 & & 6 & \\
\hline & & $<12$ atau $>32$ & 1 & & 3 & \\
\hline \multirow[t]{3}{*}{2.} & Salinitas & $10-20$ & 3 & \multirow{3}{*}{3} & 9 & \multirow{3}{*}{$\begin{array}{c}\text { Widiatmaka et al } \\
\text { (2014) }\end{array}$} \\
\hline & $(\mathrm{ppm})$ & $20-35$ & 2 & & 6 & \\
\hline & & $<10$ atau $>35$ & 1 & & 3 & \\
\hline \multirow[t]{4}{*}{3.} & Kedalaman & $60-120$ & 3 & \multirow{4}{*}{2} & 6 & \multirow{4}{*}{$\begin{array}{l}\text { Romadhona et al } \\
\text { (2015) }\end{array}$} \\
\hline & $(\mathrm{cm})$ & $80-110$ atau $120-$ & 2 & & 4 & \\
\hline & & 150 & 1 & & 2 & \\
\hline & & $<70$ atau $>150$ & & & & \\
\hline \multirow[t]{3}{*}{6.} & Kecerahan & $30-40$ & 3 & \multirow{3}{*}{2} & 6 & \multirow{3}{*}{$\begin{array}{c}\text { Cahyono } \\
\text { (2009) }\end{array}$} \\
\hline & $(\mathrm{cm})$ & $25-40$ atau $40-60$ & 2 & & 4 & \\
\hline & & $<25$ atau $>60$ & 1 & & 2 & \\
\hline \multirow[t]{3}{*}{7.} & $\mathrm{pH}$ & $6-8$ & 3 & \multirow{3}{*}{2} & 6 & \multirow{3}{*}{$\begin{array}{c}\text { Widiatmaka et al } \\
\text { (2014) }\end{array}$} \\
\hline & & 4-6 atau 8-9 & 2 & & 4 & \\
\hline & & $<4$ atau $>9$ & 1 & & 2 & \\
\hline \multirow[t]{3}{*}{8.} & DO & $4-7$ & 3 & \multirow{3}{*}{3} & 9 & \multirow{3}{*}{$\begin{array}{c}\text { Widiatmaka et al } \\
\text { (2014) }\end{array}$} \\
\hline & $(\mathrm{mg} / \mathrm{l})$ & $2,5-4$ & 2 & & 6 & \\
\hline & & $<2,5$ & 1 & & 3 & \\
\hline \multirow[t]{4}{*}{9.} & Ammonia & $0-0,03$ & 7 & \multirow{4}{*}{1} & 7 & \multirow{4}{*}{$\begin{array}{c}\text { Supratno } \\
\text { (2006) }\end{array}$} \\
\hline & $(\mathrm{mg} / \mathrm{l})$ & $>0,03-0.05$ & 5 & & 5 & \\
\hline & & $>0.005-0.008$ & 3 & & 3 & \\
\hline & & $>0.008-0,1$ & 1 & & 1 & \\
\hline \multirow[t]{3}{*}{10.} & Phosfat & $>0,21$ & 3 & \multirow{3}{*}{3} & 9 & \multirow{3}{*}{$\begin{array}{c}\text { Ramadhani et al } \\
\text { (2016) }\end{array}$} \\
\hline & $(\mathrm{mg} / \mathrm{l})$ & $0,1-0,21$ & 2 & & 6 & \\
\hline & & $0,051-0,1$ & 1 & & 3 & \\
\hline
\end{tabular}

\section{Penentuan Kelas Kesesuaian Lahan}

Penentuan klas kesesuaian lahan tambak diawali dengan menyusun matriks kesesuaian yang berisi parameter-parameter yang kualitas tanah maupun kualitas sumber air yang menjadi syarat tumbuh dan berkembangnya cultivan yang akan nantinya dibudidayakan pada tambak-tambak budidaya udang vanname di muara Sungai Sibundong Kecamatan Kabupaten Tapanuli Tengah. Kemudian menentukan batas-batas nilai untuk setiap parameter yang memenuhi persyaratan budidaya udang vanname. Pembobotan pada setiap parameter ditentukan berdasarkan pada dominannya faktor tersebut terhadap suatu peruntukan kelayakan lahan budidaya pada tambak udang vanname. Parameter tersebut diurutkan mulai dari yang paling berpengaruh terhadap suatu peruntukan yang dapat memberikan pengaruh lebih kuat bagi organisme budidaya diberi bobot lebih tinggi. Kriteria yang digunakan yang digunakan dalam penelitian ini terdiri dari 10 parameter, yakni suhu, salinitas, kedalaman dan lebar muara sungai, kecerahan, $\mathrm{pH}, \mathrm{DO}$, amonia, phosfat, dan BOD (Tabel 2). Tingkat kesesuaian terbagi atas 3 (tiga) kelas, yaitu: S3 : sangat Sesuai, kelas S2: 
sesua1, dan kelas sı: essua1 bersyarat. Kriteria skoring dan pembobotan kesesuaian lahan budidaya udang vanname dapat dilihat pada Tabel 3.

Tabel 3. Skor dan Kelas Kesesuaian Lahan serta Faktor Pembatas Untuk Pengembangan Budidaya Udang Vanname.

\begin{tabular}{|c|c|c|c|}
\hline Total Skor & Tingkat Kesesuaian & Kualitas Perairan & \\
\hline $43-63$ & S1 (Sangat Sesuai) & $\begin{array}{l}\text { Potensial, tidak mempunyai } \\
\text { penghambat }\end{array}$ & faktor \\
\hline $21-42$ & S2 (Sesuai) & Memenuhi persyaratan minimal & \\
\hline$<21$ & S3 (Sesuai Bersyarat) & $\begin{array}{l}\text { Mempunyai faktor pembatas, } \\
\text { perlakuan khusus }\end{array}$ & perlu \\
\hline
\end{tabular}

Sumber: Wibowo, 2006.

\section{HASIL DAN PEMBAHASAN}

Hasil pengukuran kualitas air ditinjau dari segi fisika, kimia di
Sungai Sibundong terangkum dalam (Tabel 4).

Tabel 4. Nilai Parameter Kualitas Air Muara Sungai Sibundong.

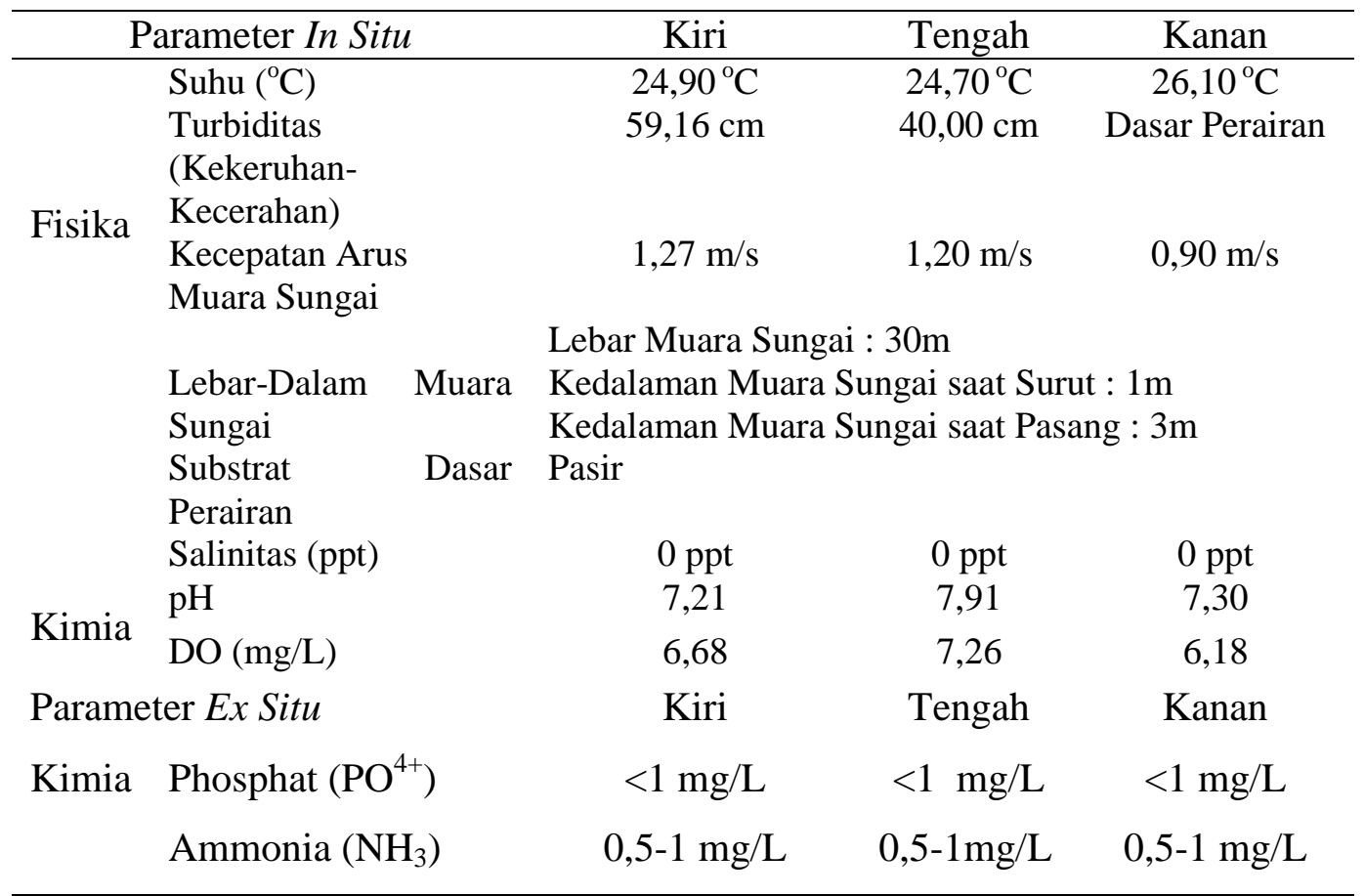

Sumber: Hasil Pengukuran dan Analisis Penelitian, 2019.

Parameter Kualitas Air Sungai Sibundong

\section{a. Faktor Fisika}

- Topografi, Elevasi, Lebar dan Dalam Muara Sungai Sibundong Muara Sungai Sibundong memiliki topografi yang landai dengan kemiringan dasar perairan $0^{\circ}$ dengan kedalaman pada saat surut mencapai $1 \mathrm{~m}$ dan pada saat pasang ataupun setelah hujan deras mencapai 3m. Daerah ini merupakan zona yang memiliki kemiringan rendah, kecepatan alir yang juga rendah serta membentuk delta (WWF, 2011, Gambar 2A). Pada 
muara sungai Sibundong banyak terbentuk delta di bagian sebelah kanan dan kiri muara sungai. Hal ini disebabkan karena derasnya luapan muara sungai pada saat setelah turun hujan ataupun banjir. Rata-rata sedimen yang terendapkan pada zona ini merupakan jenis sedimen yang sangat halus. Mulut sungai akan membentuk delta yang bersedimen dasar sangat halus dan menyebabkan sungai memiliki banyak cabang (WWF, 2011). Dimana, sedimen muara sungai Sibundong bertekstur pasir yang sangat halus yang merupakan campuran dari sedimen yang berasal dari sungai dan terumbu karang yang sudah hancur (Gambar 2B\&C). Delta pada muara sungai Sibundong dipergunakan sebagai tempat untuk mencari ikan (dengan cara memancing ikan dan menjerat kepiting dengan menggunakan bubu). Dikarenakan lebar muara sungai Sibundong yang mencapai $30 \mathrm{~m}$, delta di muara sungai tersebut juga dipergunakan sebagai tempat sandar kapal untuk dibersihkan dan persiapan logistik untuk melaut serta menjemur ikan asin (Gambar 2D). Kegiatan tersebut umumnya dilakukan pada saat air laut sedang surut ataupun tidak hujan ataupun banjir.

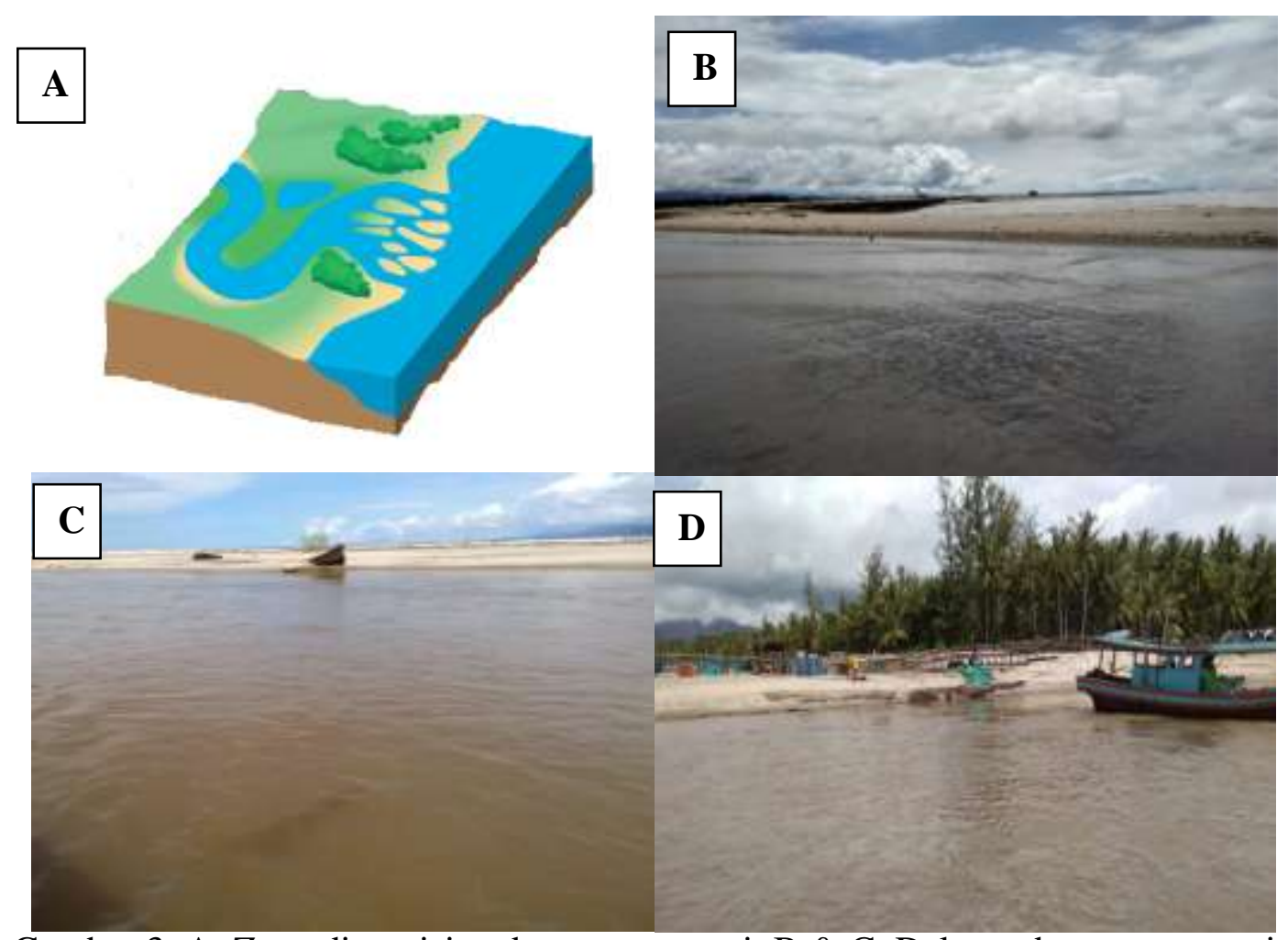

Gambar 3. A. Zona disposisi pada muara sungai. B \& C. Delta pada muara sungai Sibundong, dan D. Bagian kanan delta muara sungai Sibundong.

- Kecepatan Arus

Kecepatan arus rata-rata di muara sungai Sibundong di bagian kiri adalah $1,27 \mathrm{~m} / \mathrm{s}$, di bagian tengah adalah $1,20 \mathrm{~m} / \mathrm{s}$, dan di bagian kanan adalah $0,90 \mathrm{~m} / \mathrm{s}$. Hasil penelitian ini menunjukkan bahwa kecepatan arus air di muara sungai Sibundong termasuk cukup deras sesuai dengan hasil perhitungan kecepatan aliran rata-rata muara sungai yang dipengaruhi pasang- 
surut air laut sepert1 dalam penelitian yang dilakukan oleh Anasiru (2005). Hal ini dapat disebabkan karena penelitian dilakukan pada saat air laut surut dan setelah hujan deras sehingga aliran sungai dari daratan lebih mendominasi aliran atau keadaan air yang ada di muara sungai Sibundong.

- Turbiditas (Kekeruhan-Kecerahan)

Tingkat kekeruhan-kecerahan rata-rata di muara sungai Sibundong di bagian kiri adalah $59,16 \mathrm{~cm}$, dan di bagian tengah dalam adalah 40,00 cm, dan di bagian kanan mencapai dasar perairan. Hal ini menunjukkan bahwa perairan di muara sungai Sibundong sangat baik untuk kegiatan pengembangan budidaya udang vanname dikarenakan penetrasi cahaya matahari cukup maksimal untuk dapat mencapai kolom air untuk

\section{b. Faktor Kimia}

- Salinitas

Salinitas rata-rata di bagian kiri, tengah dan kanan muara sungai Sibundong adalah 0 ppt. Berdasarkan salinitas, badan air dapat dibedakan dalam tiga kategori, yaitu air tawar (0-3 ppt), air laut (lebih dari $20 \mathrm{ppt}$ ) dan air payau (420 ppt) (Piranti, 2015), sehingga muara sungai Sibundong masih termasuk pada kategori perairan tawar. Hal ini dikarenakan dominasi aliran air sungai Sibundong sangatlah tinggi dibandingkan dengan pengaruh dari air laut. Dimana penelitian ini dilakukan pada saat air laut sedang surut dan dalam keadaan setelah hujan deras, sehingga kadar garam pada air permukaan muara sungai Sibundong cenderung rendah. $-\mathrm{pH}$

Derajat keasaman (pH) merupakan ukuran asam basah dalam menunjang kehidupan pakan alami dari udang yang akan dibudidayakan. Dimana tingkat kekeruhan-kecerahan perairan memenuhi kecerahan optimum untuk kegiatan budidaya perikanan dalam suatu perairan yang berkisar antara 20-40 cm (Hasim, et.al., 2015).

- Suhu

Suhu rata-rata di muara sungai Sibundong berdasarkan hasil penelitian di bagian kiri adalah 24,90 ${ }^{\circ} \mathrm{C}$, di bagian tengah dalam adalah $26,10^{\circ} \mathrm{C}$, dan di bagian kanan adalah $24,70{ }^{\circ} \mathrm{C}$. Hal ini menunjukkan bahwa perairan di muara sungai Sibundong baik untuk kegiatan pengembangan budidaya perikanan payau. Dimana, suhu yang optimal untuk usaha budidaya udang vanname adalah $20^{\circ} \mathrm{C}-30^{\circ} \mathrm{C}$ (Liao \& Muarai, 1986).

suatu perairan. $\mathrm{pH}$ rata-rata muara sungai Sibundong di bagian kiri adalah 7,21 , di bagian tengah adalah 7,91, dan di bagian kanan adalah 7,30. Hasil penelitian tersebut menunjukkan bahwa muara sungai Sibundong memiliki kecenderungan memiliki $\mathrm{pH}$ yang hampir mendekati $\mathrm{pH}$ netral. Sementara keasaman air untuk reproduksi atau perkembangbiakan biasanya akan baik pada $\mathrm{pH}$ 6,4-7,0, sesuai dengan jenis organisme budidaya. Nilai $\mathrm{pH}$ juga mempunyai pengaruh yang signifikan pada kandungan amonia, $\mathrm{H}_{2} \mathrm{~S}$, $\mathrm{HCN}$, dan logam berat. Peningkatan nilai $\mathrm{pH}$ hingga 1 angka akan meningkatkan nilai konsentrasi amonia di dalam air hingga 10 kali lipat dari semula. Menurut Anonim (2003) $\mathrm{pH}$ ideal untuk kehidupan udang vanname yaitu 7.5-8.5. Selanjutnya disampaikan bahwa $\mathrm{pH}$ yang rendah dapat menyebabkan 
kenaikan toksisitas dalam suatu perairan yang lama kelamaan akan menyebabkan penurunan nafsu makan udang.

- Oksigen Terlarut (Dissolved Oxygen)

Oksigen terlarut di bagian kiri muara sungai Sibundong adalah 6,68 $\mathrm{mg} / \mathrm{L}$, di bagian tengah adalah 7,26 $\mathrm{mg} / \mathrm{L}$ dan di bagian kanan adalah $6,18 \mathrm{mg} / \mathrm{L}$. Data dari hasil penelitian menunjukkan bahwa muara sungai Sibundong dapat dimanfaatkan untuk kegiatan pengembangan budidaya organisme air payau ternasuk udang vanname. Dimana oksigen terlarut yang disyaratkan adalah 4,5-7 mg/L (Komarawidjaja, 2006).

- Phosphat $\left(\mathrm{PO}^{4+}\right)$

Kandungan fosfat di bagian kiri muara sungai Sibundong adalah $<1 \mathrm{mg} / \mathrm{L}$, di bagian tengah adalah $<1$ $\mathrm{mg} / \mathrm{L}$, dan bagian kanan adalah $<1$ $\mathrm{mg} / \mathrm{L}$. Perairan yang mengandung orthopospat antara 0,003-0,010 mg/L merupakan perairan yang oligotrofik (perairan miskin unsur hara), 0,01$0,03 \mathrm{mg} / \mathrm{L}$ adalah mesotrofik (perairan sedang unsur hara), dan 0,03-1 $\mathrm{mg} / \mathrm{L}$ adalah eutrofik (perairan kaya akan unsur hara) (Mustofa, 2015). Sehingga dapat disimpulkan bahwa muara sungai Sibundong merupakan perairan antara mesotrofik hingga eutrofik. Pengkayaan perairan ini dapat berasal dari akumulasi fosfat dari bagian tengah sungai yang didiami dan merupakan pusat kegiatan masyarakat Kecamatan Sorkam. Akumulasi pada kolom air fosfat

\section{c. Faktor Biologi}

Hasil pengamatan di laboratorium terhadap sampel air muara sungai Sibundong menunjukkan adanya jasad renik pada muara Sungai Sibundong. Perkiraan jasad renik tersebut adalah diperkaya akibat kegiatan perikanan seperti pencucian kapal, pengisian balas kapal, kegiatan mandi cuci kakus masyarakat yang berada di muara sungai Sibundong sebagai bagian Kelurahan Sorkam Kanan.

- Ammonia $\left(\mathrm{NH}_{3}\right)$

Kandungan ammonia di muara sungai Sibundong di bagian kiri adalah 0,5-1 $\mathrm{mg} / \mathrm{L}$, di bagian tengah adalah $0,5-1 \mathrm{mg} / \mathrm{L}$, dan di bagian kanan adalah 0,5-1 $\mathrm{mg} / \mathrm{L}$. Hasil penelitian ini menunjukkan bahwa muara sungai Sibundong belum layak untuk dikembangkan dalam kegiatan perikanan budidaya organisme air payau. Sesuai dengan acuan kadar ammonia yang dikeluarkan oleh Boyd, 1990, dimana sebaiknya kadar amonia di dalam wadah budidaya udang vanname tidak lebih dari $0,2 \mathrm{mg} / \mathrm{L}$ (ppm). Dimana kegiatan pencemaran bahan organik berasal dari limbah domestik dari kegiatan perikanan, perkapalan dan masyarakat yang mendiami sepanjang aliran sungai serta limpasan pupuk pertanian kelapa sawit dan palawija di sepanjang aliran sungai dari bagian hulu, tengah dan muara Sungai Sibundong. Akan tetapi, dikarenakan suhu perairan muara sungai Sibundong yang cukup rendah, menyebabkan kadar ammonia tersebut tidak bersifat mematikan bagi biota-biota yang hidup di perairan tersebut, sehingga masih dapat dipertimbangkan untuk digunakan dalam kegiatan budidaya udang vanname.

bagian serasah dari tumbuhan yang tumbuh di sepanjang aliran sungai Sibundong dari bagian hulu, tengah dan muara sungai baik yang tumbuh secara alami ataupun hasil rekayasa manusia seperti perkebunan kelapa 
sawit dan palawija. Serasah tumbuhan tersebut jatuh dan hanyut terbawa aliran sungai dan mengumpul di muara sungai. Perkiraan jenis jasad renik yang berada dalam sampel air sungai Sibundong lainnya adalah fitoplankton, zooplankton, telur ikan dan larva udang. Hal ini menunjukkan bahwa muara sungai

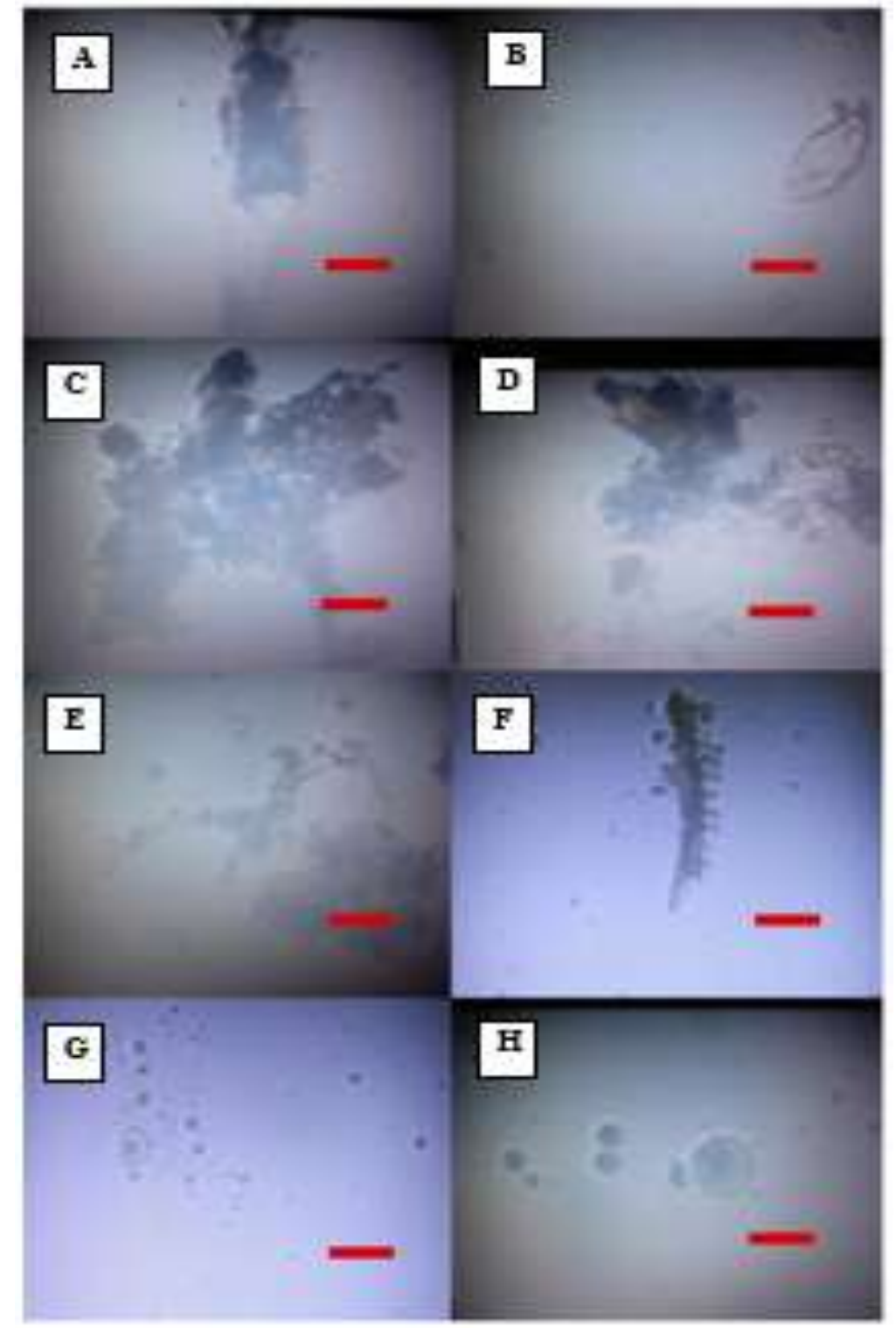

Gambar 4. Hasil pengamatan jasad renik dari air sampel penelitian yang diambil dari Muara Sungai Sibundong. A-B. Invertebrata Air, C-E. Tumbuhan air ataupun serasah tumbuhan di sepanjang aliran air muara sungai Sibundong, F. Larva udang, dan G-H. Telur ikan. Skala mewakili $1 \mu$, $40 x$. 
Evaluasi Kesesuaian Lahan Sungai Sibundong

Hasil analisis kesesuaian lahan pada lokasi penelitian di Sungai Sibundong, menunjukkan kelas kesesuaian lahan S2 (sesuai) di semua titik stasiun penelitian Sungai
Sibundong. Kelas kesesuaian lahan di Sungai Sibundong di Kecamatan Sorkam untuk pengembangan perikanan budidaya udang vanname dapat dilihat pada Tabel 5.

Tabel 5. Skor dan Kelas Kesesuaian Lahan di Muara Sungai Sibundong Kecamatan Sorkam.

\begin{tabular}{clccc} 
No & \multicolumn{1}{c}{ Lokasi } & $\begin{array}{c}\text { Skor } \\
\text { Kualitas } \\
\text { Air }\end{array}$ & $\begin{array}{c}\text { Kelas } \\
\text { Kesesuaian } \\
\text { Lahan }\end{array}$ & Kualitas Perairan \\
\hline 1. & $\begin{array}{l}\text { Muara Sungai Sibundong } \\
\text { Bagian Kiri }\end{array}$ & 36 & S2 & $\begin{array}{c}\text { Memenuhi persyaratan } \\
\text { minimal }\end{array}$ \\
2. & $\begin{array}{l}\text { Muara Sungai Sibundong } \\
\text { Bagian Tengah } \\
\text { Muara Sungai Sibundong } \\
\text { Bagian Kanan }\end{array}$ & 36 & S2 & $\begin{array}{c}\text { Memenuhi persyaratan } \\
\text { minimal }\end{array}$ \\
3. & 39 & S2 & $\begin{array}{c}\text { Memenuhi persyaratan } \\
\text { minimal }\end{array}$ \\
\hline
\end{tabular}

Strategi Pengembangan Budidaya Perairan di Muara Sungai Sibundong Komoditas yang layak dikembangkan di muara sungai Sibundong adalah udang vanname (Litopenaeus vannamei). Udang vanname termasuk ordo Decapoda, seperti halnya dengan udang windu, namun udang vanname termasuk tipe pemakan lambat tetapi terus-menerus (continous feeder) dan menyukai hidup di dasar dan semua kolam air (Haliman \& Adijaya, 2005). Udang ini memiliki banyak keunggulan dikarenakan memiliki toleransi cukup tinggi terhadap perubahan secara mendadak dari kualitas air, terutama di musim kemarau, memiliki ketahanan terhadap penyakit dan tingkat produktivitasnya tinggi (Semeru, 2009; Budiardi et.al, 2005). Selain itu, udang vanname dapat dipelihara dengan padat tebar tinggi karena mampu memanfaatkan pakan dan ruang secara lebih efisien sehingga dapat menekan biaya produksi serta meningkatkan pendapatan para pembudidaya (Mardhiani, 2017).

Mansur (2001) mengatakan bahwa produktivitas budidaya udang terutama udang windu di Indonesia mencapai puncaknya pada tahun 1991-1994. Setelah periode tersebut produksi udang budidaya semakin menurun. Hal ini karena terjadinya kegagalan panen sebagai akibat penurunan kualitas lingkungan, kesalahan dalam penerapan teknologi dan merebaknya bermacam-macam penyakit. Di sisi lain, jumlah kebutuhan konsumsi masyarakat internasional semakin meningkat. Keterbatasan jumlah pasokan dan peningkatan jumlah kebutuhan menyebabkan harga udang semakin naik. Kondisi ini merupakan peluang yang sangat baik bagi suatu daerah penghasil udang, untuk mencapai sasaran tersebut, oleh pemerintah ditetapkan beberapa langkah 
operasional yang kongkrit di antaranya adalah pengembangan udang vanname di samping udang

\section{IV.KESIMPULAN DAN SARAN}

Hasil analisis kesesuaian lahan di lokasi penelitian menunjukkan kelas kesesuaian S2 (sesuai), berdasarkan perhitungan skor dan pembobotan masing-masing kriteria dan parameter yang dipersyaratkan. Masih diperlukannya penelitian lanjutan berupa pengukuran kualitas air dengan persebaran titik ukur yang lebih banyak, pemetaan (mapping/plotting) dengan menggunakan citra satelit, dan persiapan penyediaan sarana prasarana di lokasi potensial budidaya yang akan menunjang proses produksi hingga pasca panen budidaya udang vanname di muara Sungai Sibundong.

\section{UCAPAN TERIMA KASIH}

Penelitian ini merupakan bagian dari penelitian dosen pemula di Sekolah Tinggi Perikanan dan Kelautan Matauli yang didanai sepenuhnya oleh Yayasan MATAULI. Ucapan terima kasih juga penulis ucapkan kepada Bapak Dr. Ir. Akbar Tandjung selaku pembina Yayasan MATAULI, Dr. Ir. Syukri Batubara, M.H sebagai Ketua Umum Yayasan MATAULI, Ibu Krisnina Maharani Tandjung sebagai Dewan Pengawas Yayasan MATAULI, Dr. Ir. Joko Samiaji, M.Sc sebagai Ketua Umum STPK Matauli, Bapak Boy Rahman Hasibuan, S.Ip dari Kecamatan Sorkam, Bapak Rinaldy Pasaribu dari Kelurahan Sorkam Kiri, Masyarakat Kecamatan Sorkam, Masyarakat Kelurahan Sorkam Kiri dan Dukuh III, Rekan-rekan Dosen windu, rostris, dan udang lokal lainnya (Tonnek et. al., 2005).

serta Tenaga Kependidikan, dan para mahasiswa/i STPK Matauli.

\section{DAFTAR PUSTAKA}

Anasiru, T. 2005. Analisis Perubahan Kecepatan Aliran Pada Muara Sungai Palu. Jurnal Smartek, 3(2).

Anonim, 2003. Litopenaeus vannamei sebagai alternatif budidaya udang saat ini. P.T. Central Proteina Prima (Charoen Pokphand Group).Surabaya.

Badan Pusat Statistik Kabupaten Tapanuli Tengah. 2017. Situs Resmi Badan Pusat Statistik Kabupaten Tapanuli Tengah. [Internet]. [diunduh 01 Agustus 2018].Tersediapada:https://tapa nulitengahkab.bps.go.id/dynam ictable/2017/07/05/5/pdrbkabu paten tapanuli-tengah-atasdasar-harga-konstan-2010menurut-lapangan-usahatahun2010-2016-juta-rupiah.html.

Boyd, C.E. 1990. Water Quality in Warmwater Fish Pond. Auburn University. Alabama.

Budiarti, T., T. Batara, Wahjuningrum, D. 2005. Tingkat Konsumsi Oksigen Udang Vaname (Litopenaeus vannamei) dan Model Pengelolaan Oksigen pada Tambak Intensif. Jurnal Akuakultur Indonesia, 4(1).

Cahyono, B. 2009. Budidaya Biota Air Tawar. Kanisius. Yogyakarta.

Environmental Protection (Water) Policy. 2009. Monitoring and Sampling Manual. Physical 
and Chemical Assessment. In situ Water Quality Sampling Using A Secchi Disc. February 2018 Eds. Queensland Government. Australia.

Google Earth. 2018. [Internet]. [diunduh 01 Desember 2018].Tersedia pada: https://www.google.com/earth/. Haliman, R.W., Adiwijaya, D. 2005. Udang Vanname. Seri Agribisnis. Pembudidayaan dan Prospek Pasar Udang Putih yang Tahan Penyakit. Penebar Swadaya. Jakarta.

Hasim, Koniyo, Y., Kasim, F. 2015. Parameter Fisik-Kimia Perairan Danau Limboto Sebagai Dasar Pengembangan Perikanan Budidaya Air Tawar. Jurnal Ilmiah Perikanan dan Kelautan, 3(4).

Indonesia Climate Change Trust Fund. 2018. Universitas Riau. Pekanbaru.

Komarawidjaja, W.2006. Pengaruh Perbedaan Dosis Oksigen Terlarut (DO) Pada Degradasi Amonium Kolam Kajian Budidaya Udang. Jurnal Hidrosfir, 1 (1).

Liao, I.C, Murai, T.1986. Effects of Dissolved Oxygen, Temperature, and Salinity on The Oxygen Consumption of Grass Shrimp (Penaeus monodon). In : Maclean, J.L.Dizon, L.B. and Hosillos, L.W. (Eds): The First Asian Fisheries Society, Manilla, Phillipinnes.

Mahdiani, I.R. 2017. Sistem Akuisisi Data Pengukuran Kadar Oksigen Terlarut Pada Air Tambak Udang Menggunakan Sensor Dissolved Oxygen (DO). (Skripsi). Jurusan Fisika. Fakultas Matematika dan Ilmu
Pengetahuan. Universitas Bandar Lampung.

Makkasau, 2020. Manajemen

Pelabuhan Perikanan Kota

Sibolga. Pelabuhan Perikanan

Nusantara Sibolga.

Kementerian Kelautan dan

Perikanan. Direktorat Jenderal

Perikanan Tangkap.

Disampaikan pada Kuliah

Umum di Sekolah Tinggi

Perikanan dan Kelautan

Matauli. Pandan, 10 Februari 2020.

Mansur. 2001. Potensi dan Kendala Pengembangan Budidaya Udang Vanname di Sulawesi Selatan. [Internet]. [diunduh 01 Agustus 2018]. Tersedia pada: e-journal-

balitbang.kkp.go.id/indeks.php/ $\mathrm{ma} /$ article/download/1561/122 3.

Mustofa, A. 2015. Kandungan Nitrat dan Pospat Sebagai Faktor Tingkat Kesuburan Perairan Pantai. Jurnal DISPROTEK, 6, (1).

Nazir, M. 2003. Metode Penelitian. Ghalia. Jakarta.

New, M.B. 2002. Freshwater Prawn Farming A Manual For The Culture Of Macrobrachium rosenbergii. Fisheries Technical. Food and Agriculture Organization of the United National. 428 p.

Pemerintah Kabupaten Tapanuli Tengah. 2018. Situs Resmi Kabupaten Tapanuli Tengah. [Internet]. [diunduh 01 Agustus 2018].Tersedia pada: http://www.tapteng.go.id/poten sidaerah.html?id=Kelautan_dan_ Perikanan.

Piranti, A. 2015. Baku Mutu Air Untuk Budidaya Ikan. Disertasi. 
Fakultas Biologi Universitas Sudirman. Purwokerto.

Ramadhani, F., Syahrul, P., dan T, Krairuman. 2016. Analisis Kesesuaian Parameter Perairan Terhadap Komuditas Tambak Menggunakan Sistem Informasi Geografis (SIG) Di Kabupaten Pidie Jaya. Jurnal Ilmiah Mahasiswa Kelautan Perikanan Unsyiah, 1 (1).

Richmand, 2019. Kebijakan Pembangunan Kelautan dan Perikanan Kabupaten Tapanuli Tengah. Dinas Perikanan dan Kelautan Kabupaten Tapanuli Tengah. Disampaikan Pada Kuliah Umum di Sekolah Tinggi Perikanan dan Kelautan Matauli. Pandan, 10 Februari 2020.

Romadhona, B., Y. Bambang dan Sudarno. 2015. Fluktuasi Kandungan Amonia Dan Bebas Cemaran Lingkungan Tambak Udang Vannamei Intensif Dengan Teknik Panen Parsial Dan Panen Total. Saintek Perikanan : Indonesian Journal of Fisheries Science and Technology, 11 (2).

Sumeru, S. 2009. Pakan Udang. Kanisius. Yogyakarta.

Supratno, K.P. 2006. Evaluasi Lahan Tambak Wilayah Pesisir Jepara Untuk Pemanfaatan Budidaya Ikan Kerapu. Tesis. Program Studi Magister Manajemen Sumberdaya Universitas Pantai. Semarang.

Tonnek, S., M., Mangampa, E.A. Hendrajat, Suwoyo, H.S. 2005. Kesiapan teknis dalam mendukung revitalisasi perikanan dan kelautan Sulawesi Selatan. Makalah disampaikan dalam Pertemuan
Teknis Petugas Inbud seSulawesi Selatan di Makasar, 26 Oktober 2005. 10 Halaman.

Widiatmaka, W. Ambarwulan, B. Riadi, I. Nahib, S. Budhiman and A. Halim. 2014. Spasial Multi Criteria Land Evaluation and Remote Sensing for Area Delineation of Shrimp Pond Culture Revitalization in Mahakam Delta, Indonesia. Proceeding of the 12th Biennial Conference of Pan Ocean Sensing Conference (PORDEC 2014). Bali. Indonesia. pp: 839-847.

World Fund.2011. River Ecology: Conservation, Biodiversity, and Sustainibility. WWF Danube Carpathian Programme.

Yayasan Matauli. 2018. Booklet Pengadaan Alat-alat Laboratorium Sekolah Tinggi Perikanan dan Kelautan Matauli Tahun Anggaran 2018. Pandan. Tapanuli Tengah. Sumatera Utara. 